Short Communication

\title{
Intestinal ischemia-reperfusion injury mediates expression of inflammatory cytokines in rats
}

\author{
Kristína Gregová ${ }^{1}$, Štefan Č́́koš², Miroslava Bilecová-Rabajdová ${ }^{3}$, Peter Urban ${ }^{3}$, Ján Varga ${ }^{4}$, \\ Štefan Feterik ${ }^{1}$ and Jarmila Veselá ${ }^{1}$ \\ 1 Department of Histology and Embryology, Faculty of Medicine, Pavol Jozef Šafárik University, Šrobárova 2, 04180 \\ Košice, Slovak Republic \\ 2 Institute of Animal Physiology, Slovak Academy of Sciences, Šoltésovej 4-6, 04001 Košice, Slovak Republic \\ 3 Department of Medical and Clinical Biochemistry and LABMED, Faculty of Medicine, Pavol Jozef Šafárik University, \\ Tr. SNP 1, 04011 Košice, Slovak Republic \\ 4 Department of Gynaecology and Obstetrics, Faculty of Medicine, Pavol Jozef Šafárik University, Rastislavova 43, 04190 \\ Košice, Slovak Republic
}

\begin{abstract}
The small intestine is an organ with very well developed immunological activity, responsible for synthesis of specific inflammatory mediators that participate in causing the systemic inflammation that can occur after ischemia-reperfusion injury. The aim of our work was to study mRNA expression and protein concentration of inflammatory cytokines IL-10 and TNFa in the jejunal wall after intestinal ischemia-reperfusion injury (IRI). Cytokine concentration levels confirmed the direct effect of IRI on the inflammation process. The results refer to the changes in balance between pro-inflammatory and anti-inflammatory mediators and indicate that the predominant disturbance of homeostasis after intestinal IRI is present after 1 hour of reperfusion.
\end{abstract}

Key words: Intestinal ischemia-reperfusion - Cytokines - Rat

Ischemia-reperfusion injury (IRI) of the small intestine is a very important process associated with the induction of inflammation and tissue injury. Ischemia is followed by restoration of the blood flow/reperfusion. Paradoxically, reperfusion injury is more severe and causes more damage through the production of inflammatory and apoptotic mediators and free oxygen species than ischemia itself. During IRI activated neutrophils in the blood stream cause changes in homeostasis of the organism by the administration of inflammatory mediators that could lead to multiple organ failure (MOF) (Moore et al. 2005) or even to MODS (Multiple organ dysfunction syndrome). During shock, the specific cells in the small intestine undergo extensive cell death and intestine itself is the source of the inflammatory factors (Penn and Schmid-Schonbein 2008). Reperfusion of the small intestine causes the release of the cytokines,

Correspondence to: Jarmila Veselá, Department of Histology and Embryology, Faculty of Medicine, Pavol Jozef Šafárik University, Šrobárova 2, 04180 Košice, Slovak Republic

E-mail: jarmila.vesela@upjs.sk pro-inflammatory lipids and proteins into the extravascular area. These pro-inflammatory mediators are subsequently transported by the lymph and reabsorbed back to the blood stream, where they affect the polymorphonuclear neutrophils (Moore et al. 2005; Senthill et al. 2006).

Several clinical studies point to the fact, that increased levels of circulating cytokines like TNFa, IL-10, IL-6 or IL- $1 \beta$ that are upregulated by pro-inflammatory cytokine TNFa are associated with organ dysfunction, inflammation, and are causes of death (Pellegrini et al. 1996; Struber et al. 1996; Kriegel and Amiji 2011). TNFa has an important role in inflammatory processes because through the activation of its antagonists the processes of acute and chronic inflammation phase could be blocked (Ferenčík et al. 2009). Stimuli for the expression of TNFa can be bacterial, viral, parasital, or acute ischemic origin (Huang et al. 2009; Lula et al. 2009; Roman-Campos 2009). After IRI, TNFa is synthetized by macrophages, lymphatic cells, mast cells, endothelial cells, fibroblasts and even nerve cells (Gilles et al. 2003). IL-10 is the anti-inflammatory agent, or antagonist which downregulates TNFa (Meisel et al. 
1996) and it is produced by a wide variety of cells such as macrophages, B-cells, T-lymphocytes, or monocytes. The regulation of cytokine release is carried out through a series of specific negative and positive feedback loops. Increased concentration of TNFa is involved in upregulation of IL-10 (Meisel et al. 1996). Nussler et al. (2003) stated the surprising result that the expression of IL-10, a well-known anti-inflammatory cytokine, led to increased tissue injury in the small intestine and liver.

The purpose of this study was to explore the changes in specific inflammatory cytokines, their specific roles in affecting the inflammation process and homeostasis of the organism, considering the early phases of IRI (1 hour) and comparing the results with longer reperfusion periods (24 hours and 30 days).

This study was approved by the Committee for Ethics on Animal Experiments at the Faculty of Medicine, Pavol Jozef Šafárik University, Košice, Slovakia, and the experimental protocol was approved by decision of the State Veterinary and Food Administration of the Slovak Republic No. 2843/08-221a

45 adult male Wistar rats, 3-4 months old, with approximate weight about 250-350 g, were randomly assigned into three experimental groups which underwent ischemia by complete occlusion of the mesenteric artery for one hour followed by $1 \mathrm{~h}(\mathrm{R} 1, n=10), 24 \mathrm{~h}(\mathrm{R} 24, n=10)$ and 30 days (R30, $n=10$ ) of reperfusion periods. Animals in the control group (C, $n=15,5$ in each control group) underwent laparotomy, without ischemic attack. Surgical procedure was thoroughly described by Tóth et al. (2012). After the reperfusion injury the animals were sacrificed, and two $3 \mathrm{~cm}$ long jejunal samples for RNA isolation and ELISA were taken approximately $10 \mathrm{~cm}$ from the Ligamentum Trietzi, washed with cold saline, dried and frozen thoroughly in liquid nitrogen.

Total RNA was isolated from the complete wall of the small intestine using the Trizol separation method (Invitrogen, Carlsbad, CA) and Qiagen RNeasy mini kit (Qiagen, Germany) according to the manufacturer's protocol. RNA concentration and purity were determined by spectrophotometry $\left(\mathrm{A}_{260} / \mathrm{A}_{280}\right.$ ratio) using a Biophotometer plus (Eppendorf, Germany). Total mRNA was transcripted to cDNA

Table 1. Sequences of primers used for PCR

\begin{tabular}{llc}
\hline Gene & Sequences of primers & Size (bp) \\
\hline \multirow{2}{*}{ TNFa } & $\begin{array}{l}\text { FP: GAGCCCCCAATCTGTGTCCTTCTA } \\
\text { RP: CCCCGGCCTTCCAAATAAATACAT }\end{array}$ & \multirow{2}{*}{454} \\
\cline { 2 - 3 } IL-10 & $\begin{array}{l}\text { FP: TTCCATCCGGGGTGACAATA } \\
\text { RP: CAGTAGATGCCGGGTGGTTC }\end{array}$ & \multirow{2}{*}{490} \\
\cline { 2 - 3 } GAPDH & $\begin{array}{l}\text { FP: TGGGGCCAAAAGGGTCATCATCTC } \\
\text { RP: GCCGCCTGCTTCACCACCTTCTT }\end{array}$ & \multirow{2}{*}{456} \\
\hline
\end{tabular}

by using Revert Aid H minus FirstStrand cDNA Synthesis Kit (Fermentas, Germany). Inflammatory cytokine expression in the jejunal wall was measured using PCR amplification for 30 cycles. For TNFa, an initial denaturation step at $94^{\circ} \mathrm{C}$ for $5 \mathrm{~min}$ was followed by 30 cycles of $94^{\circ} \mathrm{C}$ for $30 \mathrm{~s}, 64.2^{\circ} \mathrm{C}$ for $60 \mathrm{~s}$ and $72^{\circ} \mathrm{C}$ for $45 \mathrm{~s}$. For IL-10, an initial denaturation step at $94^{\circ} \mathrm{C}$ for $5 \mathrm{~min}$ was followed by 30 cycles of $94^{\circ} \mathrm{C}$ for $30 \mathrm{~s}, 52.5^{\circ} \mathrm{C}$ for $60 \mathrm{~s}$ and $72^{\circ} \mathrm{C}$ for $45 \mathrm{~s}$. GAPDH was used as a reference gene, initial denaturation step at $94^{\circ} \mathrm{C}$ for $5 \mathrm{~min}$ was followed by 30 cycles of $94^{\circ} \mathrm{C}$ for $30 \mathrm{~s}, 55.4^{\circ} \mathrm{C}$ for $60 \mathrm{~s}$ and $72^{\circ} \mathrm{C}$ for $45 \mathrm{~s}$. The primers had the following sequences (Tab. 1). RT-PCR products were separated electrophoretically on $0.8 \%$ agarose gels, stained with EvaGreen (Fermentas, Germany), and DNA band intensities were measured using G:BOX Chem, SyngeneTools Software. Each sample was done three times. For protein assay, tissue with approximate weight of 30-80 mg was homogenized in PBS, with $30 \mathrm{mg}$ of tissue homogenize in $400 \mu \mathrm{l}$ of PBS $+2 \mu$ proteinase inhibitor (Sigma, Germany), and right after homogenization another $400 \mu \mathrm{l}$ of PBS $+2 \mu \mathrm{l}$ of proteinase inhibitor was added. After centrifugation $\left(8000 \mathrm{rpm} / 8 \mathrm{~min} / 4^{\circ} \mathrm{C}\right)$, the supernatant was collected and diluted 1:4 in sample diluent present in the kit (Platinum ELISA rat IL-10 and TNFa, eBioscience, Bender Medsystem, Austria). Cytokine assays were performed as described in the manufacturer's protocol. Each reaction in the kit was done in duplicate. Data analyses were performed using $\mu$ Quant Reader (Biotech) operating Gen5 software. For quantification of total protein in tissue, Bradford Assays were performed. Data are presented as mean \pm standard error of the mean (SEM). One way analysis of variance (ANOVA) and Student-Newmann-Keuls tests were used for comparison of the experimental groups. The significance level was established as $p \leq 0.05$ for all the tests. Statistical analysis was evaluated using the GraphPadInSTAT programme.

In this experiment, we focused on observing the early stages of intestinal IRI with regard to cytokine release. We observed the direct effect of the early phases of IRI on the mRNA levels of inflammatory cytokines TNFa and IL-10. We studied the levels of cytokines after 1 hour, 24 hours and 30 days of reperfusion comparing with control groups. We observed significantly increased mRNA expression of antiinflammatory cytokine IL-10 (Fig. 1) which correlated with the concentration of proteins in the tissue (Tab. 2) in experimental groups after 1 hour and 30 days of reperfusion. As regards pro-inflammatory cytokine TNFa, significant changes in mRNA expression (Fig. 2) had similar tendencies as changes in protein concentration (Tab. 2) after 1 hour of reperfusion. We can assume that the highest differences in expression of both cytokines were present after 1 hour of reperfusion probably as a direct reaction to the ischemic attack. As it could be seen in the results (Tab. 2) the protein concentration in control group 1 hour after reperfusion 
A

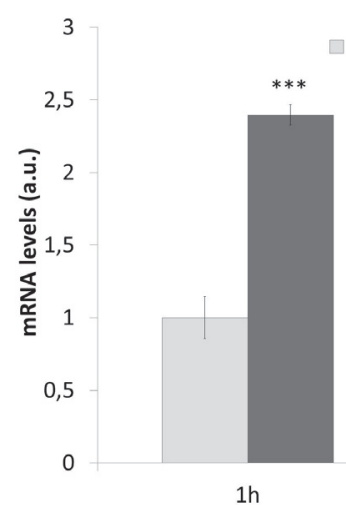

B

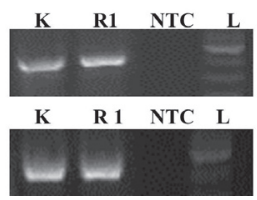

IL-10

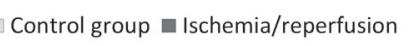

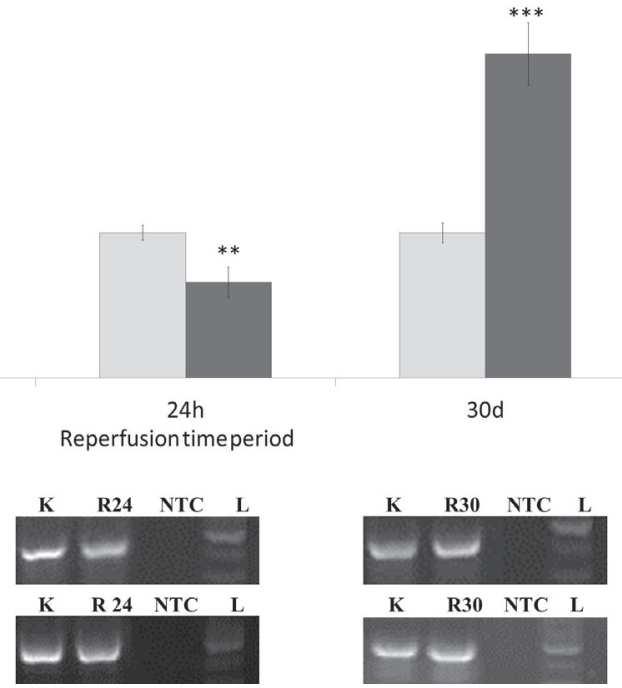

Figure 1. mRNA levels of IL-10 in rat small intestine after ischemia/reperfusion injury. A. Semiquantification graph of gene expression. Results are presented as mean \pm SEM. ${ }^{* * *} p<0.001 ;^{* *} p<0.01$ significantly different as compared to controls. C1, C24, C30, control groups underwent laparotomy without ischemic attack, 1 hour, 24 hours and 30 days after laparotomy organs were harvested; R1, R24, R30, experimental groups underwent 1 hour ischemia with following reperfusion period of 1 hour, 24 hours and 30 days. B. Detected bands for IL-10 and GAPDH. For PCR reaction was used negative control (NTC) and band position was determined against the ladder (L), experimental groups (R) compared to controls (K). increased in comparison to control groups after $24 \mathrm{~h}$ and 30 days of reperfusion, the laparotomy itself probably caused the increase in pro-inflammatory TNFa protein concentration. These results correspond with several other studies demonstrating the role of IRI in cytokine expression (Deitch et al. 1994; Nussler et al. 2003; Souza and Teixeira 2005). Souza et al. stated that TNFa plays an essential role in promoting tissue injury after IRI, and they also indicated that the degree of tissue injury is determined by the balance between TNFa and its antagonist IL-10. It is believed that the expression of anti-inflammatory cytokine IL-10 increases after IRI, which corresponds with our results. Several studies have shown that there were increased levels of TNFa and IL-10, not only in the jejunal wall but also
A

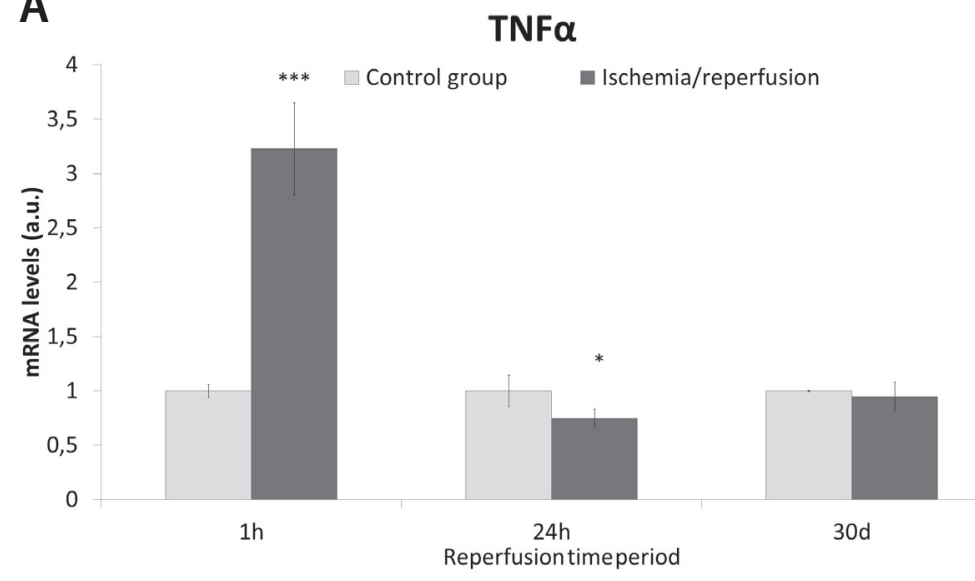

B

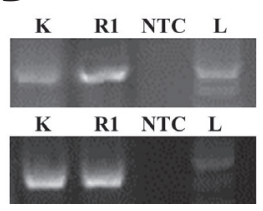

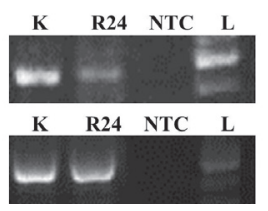

Figure 2. mRNA levels of TNFa in rat small intestine after 1 hour ischemia and subsequent reperfusion injury. A. Semiquantification graph of gene expression. Results are presented as mean \pm SEM. ${ }^{* *} p<0.001$; ${ }^{\star} p<0.05$ significantly different as compared to controls. C1, C24, C30, control groups underwent laparotomy without ischemic attack, 1 hour, 24 hours and 30 days after laparotomy organs were harvested; R1, R24, R30, experimental groups underwent 1hour ischemia with following reperfusion period of 1 hour, 24 hours and 30 days. B. Detected bands for TNFa and GAPDH. For PCR reaction was used negative control (NTC) and band position was determined against the ladder (L), experimental groups (R) compared to controls (K). 
Table 2. Concentration of anti-inflammatory cytokine IL-10 and pro-inflammatory cytokine TNF $(\mathrm{pg} / \mathrm{ml})$ after various periods of reperfusion

\begin{tabular}{lcccccc}
\hline & C1 & R1 & C24 & R24 & C30 & R30 \\
\hline IL-10 & $88.6 \pm 10.5$ & $154.86 \pm 2.7^{* * *}$ & $84.95 \pm 5.9$ & $152.96 \pm 18.5^{\star}$ & $51.26 \pm 0.12$ & $160.34 \pm 14.5^{* * *}$ \\
TNFa & $178.92 \pm 9.9$ & $513.42 \pm 55.4^{* * *}$ & $88.76 \pm 10.06$ & $294.69 \pm 12.68^{* * *}$ & $92.82 \pm 4.56$ & $228.06 \pm 12.12^{* * *}$ \\
\hline
\end{tabular}

${ }^{* * *} p<0.001,{ }^{*} p<0.05 v s$. control groups. C1, C24, C30 - control groups underwent laparotomy without ischemic attack, 1 hour, 24 hours and 30 days after laparotomy organs were harvested; R1, R24, R30 - experimental groups underwent 1 hour ischemia with following reperfusion period of 1 hour, 24 hours and 30 days.

in distant parenchymatous organs such as lungs, liver and kidneys (Oltean et al. 2009; Park et al. 2011). We can conclude that IRI directly affects the levels of pro-inflammatory cytokine TNFa as well as anti-inflammatory cytokine IL-10. The antagonistic effect of IL-10 and TNFa is well known, since through increase in IL-10 level the synthesis of TNFa is inhibited (Zingarelli et al. 2001). However, Yuan et al. (2011) observed increased levels of serum TNFa 2 hours after reperfusion, although the levels of serum IL10 decreased in comparison to control. The concentration of pro-inflammatory TNFa on protein level in our study was significantly highest 1 hour after reperfusion, similarly to Mondello et al. (2010), whereas after 24 hours and 30 days of reperfusion it showed decreasing tendency probably because of the started regeneration processes. As regards anti-inflammatory IL-10, we observed increased mRNA expression as well as protein concentration 1 hour after reperfusion, probably due to its ability to partially suppress the inevitable inflammatory reaction. In fact, 30 days after reperfusion the mRNA levels of IL-10 were lower, but concentration of particular protein in the tissue significantly increased. We suppose, the mRNA expression of IL-10 was inhibited because of the started regeneration and reparative processes. The concentration of released active protein in intestinal tissue was still high, even though the mRNA expression was probably silenced. We can assume that significant increase in the levels of both cytokines could be understood as a result of the effort of maintaining the balance in the small intestinal wall.

In conclusion, our results proved that intestinal IRI has a direct effect on the production of inflammatory mediators, mostly in the early stages after the procedure. However, after a longer reperfusion period (30 days) the regeneration processes in the small intestine have started and the expression levels of inflammatory mediators are decreased. It is necessary therefore to study efficient protective strategies with regard to the early phases of IRI. Increased understanding of IRI molecular mechanisms can result in better, more detailed and efficient therapeutic processes leading to the protection of the organism.

This experimental study was supported by the grant projects APVV-0252-07 and CEMIO-ITMS-26220120058.

\section{References}

Deitch E. A., Xu D., Franko L. (1994): The evidence favoring the role of the gut as a cytokine-generating organ in rats subjected to hemorrhagic shock. Shock 1, 141 http://dx.doi.org/10.1097/00024382-199402000-00010

Gilles S., Zahler S., Welsch U., Sommerhoff C. P., Becker B. F. (2003): Release of TNF- $\alpha$ during myocardial reperfusion depends on oxidative stress and is prevented by mast cell stabilizers. Cardiovasc. Res. 60, 608-616

http://dx.doi.org/10.1016/j.cardiores.2003.08.016

Ferenčík M., Hulín I., Štvrtinová V. (2009): Mediátory zápalu. In: Hulínova Patofyziológia. (Ed. I. Hulin), pp. 29-42, SAP, Bratislava (in Slovak)

Huang C. H., Vallejo J. G., Kollias G., Mann D. L. (2009): Role of the innate immune system in acute viral myocarditis. Basic Res. Cardiol. 104, 228-237 http://dx.doi.org/10.1007/s00395-008-0765-5

Kriegel C., Amiji M. (2011): Oral TNF-a gene silencing using a polymeric microsphere-based delivery system for the treatment of inflammatory bowel disease. J. Control. Release 150, 77-86 http://dx.doi.org/10.1016/j.jconrel.2010.10.002

Lula J. F., Rocha M. O., Nunes M. C., Ribeiro A. L., Teixeira M. M., Bahia M. T. (2009): Plasma concentrations of tumour necrosis factor-alpha, tumour necrosis factor-related apoptosis-inducing ligand, and FasLigand/CD95L in patients with Chagas cardiomyopathy correlate with left ventricular dysfunction. Eur. J. Heart Fail. 11, 825-831 http://dx.doi.org/10.1093/eurjhf/hfp105

Meisel C., Vogt K., Platzer C., Randow F., Liebenthal C., Volk H. D. (1996): Different regulation monocytic tumor necrosis factor $\alpha$ and interleukin 10 expression. Eur. J. Immunol. 26, $1580-1586$ http://dx.doi.org/10.1002/eji.1830260726

Mondello S., Galuppo M., Mazzon E., Domenico I., Mondello P., Carmela A., Cuzzocrea S. (2010): Glutamine treatment attenuates the development of ischemia/ reperfusion injury of the gut. Eur. J. Pharmacol. 643, 304-315 http://dx.doi.org/10.1016/j.ejphar.2010.06.044

Moore E. E., Moore F. A., Harken A. H. (2005): The two-event construct of post-injury multiple organ failure. Shock $\mathbf{2 4}$, (Suppl. 1), 71-74 http://dx.doi.org/10.1097/01.shk.0000191336.01036.fe

Nussler N. C., Muller A. R., Weidenbach H. (2003): IL-10 increases tissue injury after selective intestinal ischemia/reperfusion. Ann. Surg. 238, 49-58 
http://dx.doi.org/10.1097/01.sla.0000074962.26074.d3

Oltean M., Zhu C., Mera S., Pullerits R., Mattsby-Baltzer I., Molne J., Hallberg E., Blomgren K., Olausson M. (2009): Reduced liver injury and cytokine release after transplantation of preconditioned intestines. J. Sur. Res. 154, 30-37

http://dx.doi.org/10.1016/j.jss.2008.05.015

Park S. W., Chen S. W. C., Kim M., Brown K. M., Kolls J. K., D'Agati V. D., Lee T. H. (2011): Cytokines induce small intestine and liver injury after renal ischemia or nephrectomy. Lab. Invest. 91, 63-84 http://dx.doi.org/10.1038/labinvest.2010.151

Pellegrini J. D., Puyana J. C., Lapchak P. H., kedys K., Mille-Graziano C. L. (1996): A membrane TNF- $\alpha /$ TNFR ratio correlates to MODS score and mortality. Shock 6, 389-396 http://dx.doi.org/10.1097/00024382-199612000-00001

Penn A. H., Schmid-Schonbein G. W. (2008): The intestine as source of cytotoxic mediators in shock: free fatty acids and degradation of lipid binding proteins. Am. J. Physiol. Heart-C. 294, H1779-1792

Roman-Campos D., Duarte H. L., Sales P. A. Jr., Natali A. J., Ropert C., Gazzinelli R. T. (2009): Changes in cellular contractility and cytokines profile during Trypanosoma cruzi infection in mice. Basic Res. Cardiol. 104, 238-246 http://dx.doi.org/10.1007/s00395-009-0776-x

Senthill M., Brown M., Xu D. Z. (2006): Gut-lymph hypothesis of systemic inflammatory response syndrome/multiple-organ dysfunction syndrome: validating studies in a porcine model. J. Trauma 60, 958-965 http://dx.doi.org/10.1097/01.ta.0000215500.00018.47

Souza D. G., Teixeira M. M. (2005): The balance between the production of tumor necrosis factor- $\alpha$ and interleukin 10 determines tissue injury and lethality during intestinal ischemia and reperfusion. Mem. I. Oswaldo Cruz 100, 59-66 http://dx.doi.org/10.1590/S0074-02762005000900011

Stüber F., Petersen M., Bokelman F., Schade U. (1996): A genomic polymorphism within the tumor necrosis factor locus influences plasma tumor necrosis factor - concentrations and outcome of patients with severe sepsis. Crit. Care Med. 24, 381-384 http://dx.doi.org/10.1097/00003246-199603000-00004

Tóth Š., Jonecová Z., Varga J., Staško P., Kovalčinová B., Maretta M., Veselá J. (2012): Mesenteric ischemia-reperfusion injury: Specific impact on different cell populations within the jejunal wall in rats. J. Act. His. 114, 276-284 http://dx.doi.org/10.1016/j.acthis.2011.06.004

Yuan Y., Guo H., Zhang Y. (2011): Protective effects of L-carnitine on intestinal ischemia/reperfusion injury in a rat model. J. Clin. Med. Res. 3, 78-84

Zingarelli B., Yang Z., Hake P. W., Denenberg A., Wong H. R. (2001): Absence of endogenous interleukin 10 enhances early stress responseduring postischaemic injury in mice intestine. Gut 48, 610-622 http://dx.doi.org/10.1136/gut.48.5.610

Received: June 27, 2014

Final version accepted: September 16, 2014

First published online: November 14, 2014 